\title{
The current situation of Service Industry and Countermeasures of Wuhan City
}

\author{
GuYi ${ }^{1}$, Dong Liang ${ }^{2^{*}}$ \\ ${ }^{1}$ Golf school, Jianghan University, Wuhan, Hubei, China, 430056 \\ 275939829@qq.com \\ ${ }^{2}$ Business school, Jianghan University, Wuhan, Hubei, China, 430056 \\ Manufacturing Industry Development Research Center on Wuhan City, Wuhan, Hubei, China, \\ 430056, sxyld@163.com
}

Key words: service industry; economic growth; industrial structure; policy

\begin{abstract}
Along with the economic development and economic globalization, the world has entered the era of knowledge economy. The global industrial structure has changed from second third first to third second first. In particular, the service industry accounts for about 70\% of GDP in developed countries, which has reached third second first. But the third industry GDP and the number of employees accounted for 50\% of the overall economy, far less than Shanghai, Beijing and other more developed cities have reached about $75 \%$. The paper analysis the current situation of wuhan service industry, and point out the policy suggestions accordingly for the future development of Wuhan city service industry, the choice of its development mode has important effect on the development of regional economy.
\end{abstract}

\section{Introduction}

This paper is mainly divided into two parts. The first part introduces service industry's contribution to economic development, the gap between the city of Wuhan and the major cities of China on service industry development and the problems of the service industry in Wuhan; The second part contains some policy suggestions to promote the development of Wuhan service industry through detailed investigation, aiming to catch up with the well developed city's level.

\section{The Current Situation of the Development of Service Industry in Wuhan City}

Basic Survey. World Bank development report pointed out that in 1998 the total output value of the global service industry reached $61 \%$ in the proportion of economic output, the developed countries have reached more than $70 \%$, the United States is more than $80 \%$. The proportion of employment in service industry has been steadily rising, the proportion of service industry in major developed countries is close to $75 \%$. Not only that, the service has become a symbol of national economic modernization, developed countries in the financial, education, transportation, science and technology, foreign trade, health sports and other aspects have a strong strength, and these industries constitute the basis for improving the comprehensive national strength of the developed countries.

Wuhan is located in the middle China economic geography, is the main force of the central economy in China, known as the "thoroughfare of nine provinces. Convenient land, water and air transport are the main pillar of the rise of Wuhan. Wuhan has a railway, highway, water and air "multimodal transport" in the transportation network, it is one of the four national railway transportation hub (Beijing Guangzhou railway, Beijing Guangzhou Passenger Dedicated Line 
north-south, Wu nine lines, Handan railway line and the huhanrong passenger corridor connecting the East Kai West), is the six road passenger transportation network in the heart of high-speed passenger dedicated line from Shanghai, Beijing, Guangzhou just 3.5 hours and is the 16th National Congress of the Communist Party of China container base of (Yangluo Xingang container terminal capacity in the country ranked first in the country among 84). Wuhan aviation port is the fourth major airports after Beijing, Shanghai and Guangzhou. With the 2011 stone Wu passenger dedicated line, Wuhan city circle intercity railway and other 22 railway projects, Wuhan will be the national railway "two vertical and two horizontal" intersection, the main hub and Passenger Center, 4 to 5 hours to reach 1000 kilometers around the city [1,2], Wuhan railway hub of radiation across the country. And the recent rapid development of the construction of Wuhan city circle, that is, half an hour direct to the $1+8$ city circle, the greater the service also provides the basis for Wuhan. Wuhan's biggest advantage lies in scientific research and education, the abundant resources for the construction of Wuhan modern service industry center provides a strong technical and personnel support. Wuhan has abundant resources of science and education, high intelligence, high level of human resources, advanced information technology to provide a strong guarantee for the development of modern service industry in Wuhan.

With the deepening of opening up, the scale of the service industry in Wuhan has expanded, the proportion and the level of it is greatly improved, and the increase of 7.5:64:28.4 in 1960 turnef to $3.1: 46: 51$ in 2010.From second third first industrial structure to third second first. Wuhan five central city service industry increase in the proportion of GDP accounted for more than $60 \%$ : Jianghan District, help the development of modern service industry, with the advantages of commercial center, the five city in the service industry leader, GDP of its service industry accounted for 88\%; Jiang'an District, many municipal above bank headquarters and the Province largest securities, trust, futures company, the service industry accounted for $75 \%$ of the proportion of; and Wuchang District, is a university city, most of the research institutions and almost all of the gathered here, gathered a large number of cultural and creative company and training institutions, with the development of science, technology and education, to become a base for the culture and education industry, the service industry accounted for $79 \%$. From this we can see that the service industry has become the main force in the development of Wuhan [3].

\section{Development Stage of Service Industry}

National Overall Situation. Since the founding of the PRC, service industry continues to develop, and the structure is constantly changing, from the initial personal and family services, to the current information education and other industries, but compared with the world as a whole, the proportion of China's service industry is serious. 1990 to 2010 years, China's service industry within the industry accounted for the proportion of value added services decline in the industry: Wholesale and retail trade and catering industry, finance and insurance, transport, storage and communications industry, geological prospecting and water conservancy, state organs, party and government organs and social organizations in the service sector, decline in the most significant is the financial insurance industry has dropped by $10.3 \%$. But some of the industry has risen, the social services, real estate, scientific research and integrated technology services, education and culture and arts and culture of the film and television industry, the rise of social services is the most significant, an increase of $26 \%$. These trends on the whole with the international trend of the overall structure of the same, but the finance and insurance industry is opposite, the proportion of international finance and insurance industry is rising, currently appears to be because of the financial insurance industry is still in its infancy, and there is no foreign finance and insurance industry developed relatively perfect, in recent years, the Chinese government some important areas of trade in services published new on the market access of foreign investment laws and regulations, further improve market, made 
a series of preferential policies to attract foreign investment, the proportion of the financial insurance industry in the service industry as a whole marked the beginning of the rise.

We can see the basic law of economics from the internal structure evolution of its service industry, that is, the need to change the supply, and in the entire structure of the industry in which the mutual restriction and mutual promotion, rather than an independent development or backward single individual. The development of service industry is to change according to the economic development, and the service industry also promotes and changes the economic development mode and speed. Capital intensive, technology intensive service industry in the economy of the proportion of output value rose rapidly, status and role is also rising, becoming the focus of economic development of the industry [4].

Table 1. Service industry in different stages of economic development

\begin{tabular}{|c|c|c|c|}
\hline & & $\begin{array}{l}\text { The average per } \\
\text { capita income }\end{array}$ & Key industries \\
\hline \multicolumn{2}{|c|}{$1949-1960$} & $350-1400$ & Personal services, family services, etc. \\
\hline \multirow[t]{3}{*}{$1960-2000$} & $1960-1978$ & $1500-4000$ & $\begin{array}{l}\text { Public facilities: commercial, transportation, } \\
\text { communications, finance, securities }\end{array}$ \\
\hline & $1978-1990$ & $4000-10000$ & Producer services: advertising, consulting, planning \\
\hline & $1990-2000$ & $10000-30000$ & Personal services: real estate, tourism, entertainment \\
\hline \multicolumn{2}{|c|}{ Since 2000} & $30000-150000$ & $\begin{array}{l}\text { Information Industry: education research, } \\
\text { communication }\end{array}$ \\
\hline
\end{tabular}

Source: Huang Shaojun, "service industry and economic growth", Economic Science Press, 2010, 214-215.

Development Phase of Service Industry in Wuhan. Before 1978, Wuhan industrial economy suffered an unprecedented severe damage, and agriculture is the main body of the Wuhan economy, while the service industry is almost no proportion, the foundation is weak, the productivity level is low, the most important service is only commercial retail, catering, transportation, etc.. $\mathrm{n}$ the early days of the founding of the PRC, Wuhan has opened two channels, such as the Soviet Union, Eastern Europe and other countries, South to Southeast Asia and Europe, relying on two traffic to the Wuhan service industry added value in the three industrial structure is still the main. To the later great leap forward and the cultural revolution, the conservative single business management system has seriously affected the circulation of commodities in Wuhan, the proportion of industrial added value increased rapidly, the proportion of the service industry is at a standstill period.

From 1978 to 1998 , with the focus of the party's work gradually transferred to the economic construction, the national understanding of the service industry has increased rapidly in Wuhan, but in 1984, the central put forward third industrial policy, put forward to promote the development of Wuhan, Hubei and the entire central region of economic development, the adoption of the strategic thinking to promote the steady development of the third industry in Wuhan city. After the establishment of the socialist market economic system in 1989, the Wuhan third industry increased rapidly, especially in 1998, the proportion of third industries accounted for the first time more than second industries, the proportion of the three industry is 7.6:44.9:47.5, forming a "third second first" industry bureau.

After 1998, the science and technology progress accelerated, the market, the industry, the internationalization promotes the service industry globalization booming. Wuhan as the central rise strategy, Wuhan city circle, two oriented social construction comprehensive reform pilot area and East Lake National Independent Innovation Demonstration Zone, to undertake high-end industry 
transfer, enhance innovation capability, accelerate industrial restructuring and upgrading, transportation, wholesale and retail trade catering and other traditional service industry steady development, information, tourism, real estate, computer services, advertising and other emerging business services continue to expand. 1998-2010 Wuhan third industry accounted for GDP accounted for more than second industries, the average annual rate of $49.8 \%$, close to half; third industry increased by an average of $16.03 \%$, higher than the GDP growth rate of $14.96 \%$.

1950 - 2010 Wuhan GDP growth rate, third industry growth rate

\section{Research on the Development of Service Industry in Wuhan}

Overall Status has been Improved, and Promote the Development of Urbanization. Wuhan service industry plays an important opportunity to achieve rapid development. From 2002 to 2010, the proportion of fixed assets investment in Wuhan's service industry accounted for $71.9 \%$ of the total investment in fixed assets in Wuhan, and the service industry has become the core of economic and social development in Wuhan. Due to the strong development of the construction of the city circle, the main investment in the service industry for the transport, storage, post and telecommunications industry, the infrastructure investment amounted to L 128.02_yi billion, based on Inter City railway, rail transportation, highway network, Wuhan Newport transport completed investment 38.583 billion yuan, 39.2\% increase over the previous year. And the industrial structure adjustment for 3:46:51, 51, service industry in Wuhan City, the national economy has more than half, the contribution to the economic development of Wuhan City, the pace of economic service is steady.

It is the rapid development of the service industry, providing a large number of jobs, is to ease the pressure of social employment in Wuhan city can not be ignored. Service industry practitioners 2442700 people, accounting for $50.1 \%$ of the whole society, the average annual increase of nearly 81400 people. Service industry town unit on-the-job worker wages higher than the city's second industry overall level, and become the main areas of the income of the residents. Although the service industry has become an important force in the economic development of Wuhan, but the overall size of the need to develop, because from the perspective of economic value added, the increase in the value of the service industry in Wuhan, the average level of nearly 70 billion RMB more than the major cities, its growth rate is lower than Dalian 1.9\%. From GDP point of view, the service industry GDP and the employment population should be in the overall $70 \%$, but only about 50 of Wuhan, but also far from the world level, compared with the same economic development of Nanjing, but also low $12 \%$.

Urbanization is the process of transferring the population and other economic factors from the agricultural sector to the non agricultural sector, which is the fundamental symbol of the decline in the proportion of agriculture and the increase of the proportion of non agriculture, and then continue to create consumer demand, investment demand, for economic growth to put enough and stable, sustainable power source. We know that in the era of industrialization, the proportion of employment in the service sector has increased significantly, which has led to the proportion of non-agricultural employment, with the urbanization, people's demand for higher quality of higher quality, and service industry to promote the improvement of urban and soft facilities and the improvement of people's living standards, cultural education, sports entertainment, health care and other industries to provide life services. These have improved the image of the city, while the service industry, such as finance, securities, logistics, insurance, communication and storage, education and other industries to provide supporting services to enterprises, thereby promoting the development of enterprises, but also to further accelerate the urbanization, and promote the development of a harmonious society. 
Industrial Structure Change, Promote the Harmonious Development of Society. We know that the industrial structure determines the size of the total economy in a certain extent, when the industrial structure is fixed, and in the economic development to a certain size, so that its economy is to further realize the growth and expansion, is very difficult, and even impossible. In order to ensure the sustainable expansion of the economic scale, only the economic structure is continuously optimized. And this is the Wuhan city in recent years in continuous improvement, service industry internal structure has been continuously optimized adjustment, although the current from Wuhan is the whole, still to wholesale and retail, trade, accommodation and catering industry as the main development features, this is because the proportion of traditional service industry is larger, and there is much room for development, but with the development of the city, the continuous improvement of education technology, information software, modern logistics, tourism and exhibition, etc..

Table 2. Internal structure of service industry in Shenzhen, Beijing and Wuhan in 2009 (\%)

\begin{tabular}{|c|c|c|c|}
\hline Industry & Wuhan & Beijing & Shenzhen \\
\hline Traditional service industry & 35.73 & 25.54 & 31.5 \\
\hline Transportation, storage and postal & 10.16 & 6.06 & 7.34 \\
\hline Wholesale and retail & 17.88 & 16.61 & 19.74 \\
\hline Accommodation and catering & 7.69 & 2.86 & 4.43 \\
\hline Modern service industry & 64.27 & 74.76 & 68.5 \\
\hline Finance & 13.72 & 17.47 & 26.3 \\
\hline Real estate & 6.87 & 11.58 & 13.4 \\
\hline $\begin{array}{c}\text { Information transmission, computer } \\
\text { service and software industry }\end{array}$ & 6.72 & 11.62 & - \\
\hline
\end{tabular}

The three major cities in the comparison, Wuhan's share of the largest proportion of the financial industry, the real estate industry, although the proportion of modern service industry is relatively low, but compared with Beijing City, to develop into an international metropolis, the proportion of modern service industry is low, nearly $10 \%$, Wuhan city modern service industry has characteristics, such as computer services and software industry, information transmission, information transmission, accounting for $6.72 \%$. In proportion to the overall service industry accounted for more than $70 \%$, we can See, there is still a big gap on the Wuhan City, not to mention the 8 cities around the city of Wuhan, however, is because of the development of Wuhan's service industry, especially the development of modern service industry, and its development can drive the development of other cities in the city circle, and then form a real central rise.

The core content of industrial structure optimization is to adapt to the change of demand structure, service industry can not only specify the direction of industrial and agricultural production, accurate grasp the direction of industrial and agricultural production structure, but also can make industrial and agricultural output to avoid the blindness of production, and therefore more suitable for the needs of the structure of the structure of the entire industrial structure plays an important role. Service industry in the development of science and technology promote product innovation, to generate new customer needs, production of new industrial clusters, which has a big impact on the industrial structure, we can see not only the industrial structure of the economy, the economic impact of industrial structure, the industry will be enough itself is mutual constraints. Especially now is the information age, the development of information technology is the technology level of service industry continues to improve, become a service industry leading industry, as a service industry, not only can move forward, but can backward contact, promote the application of science and technology. 
Radiation Ability of Service Industry in Wuhan. The city of Wuhan city circle in Wuhan as the center is composed of nine cities of Wuhan and the surrounding a range of $100 \mathrm{~km}$ in Huangshi, Ezhou, Huanggang, Xiaogan, Xianning, Xiantao, Tianmen, Qianjiang and other regional economic union, Hubei is the economic development of the core area. Modern Wuhan service industry has the characteristics of modernity, knowledge, high technology, high value added and innovation. It has important significance for the construction of sentencing society. These services are mainly high knowledge, high-tech industries, such as finance, information industry, education, and so on, these industries are low energy consumption, high added value. Wuhan city circle has a wealth of talent, deep cultural heritage, unique geographical advantages, Wuhan has laid a solid foundation for the development of service industry. And the service industry in Wuhan city circle plays an important role in the national economy. With the Wuhan city circle planning and development, the overall industry pattern of the city circle, as the core city of the city, Wuhan has been the focus of service industry in the financial, logistics, information, education and other value-added services, and the service industry added value, and the rest of the eight cities of service industry development is still very imperfect, and it is the development of the industry structure in the layout provides the opportunity to reduce the loss in the industry pattern. Therefore, the role of the inter city service industry interaction, the strongest role in Huanggang and Ezhou, the three cities of science and technology services sector launched the industry alliance of urban services industry, to provide a large number of high-quality personnel, technology as a link, to promote the cooperation of high efficiency enterprises, the formation of the service industry's radiation development.

But the role of the inter city service industry is not balanced, Wuhan far stronger in eight other cities and, skates service quality is not high, small-scale, because there is no very norms and regulations, some of the modern service industry market dysplasia, and eight other cities agriculture occupies considerable proportion, and these personnel corresponding inhibited the demand for services, reduce the space for the development of service industry.

The Development of Wuhan City Service Industry Problems. According to Wuhan's own characteristics, the main service industries in Wuhan are the educational industry, computer service and software, and other scientific research services, wholesale and retail, traditional services (transportation, accommodation, catering, entertainment), these four categories. According to the characteristics of this accumulation, we consider from two aspects: technology and capital. The rapid development of capital intensive service industry will reduce the dependence of economic growth on investment. Changes in the internal structure of the service industry, will reduce the service industry to the extent of the investment. China's high growth phase mainly depends on the investment of industrialization brought about by rapid growth, with the increase of service industry and the decline of the role of investment, the overall investment growth may gradually decline, thereby reducing economic potential growth.

For high tech industries, similar to the education industry, this industry has a good income, but because the technology is very high, the need for a large number of talents. And Wuhan City, the University gathered, the education market. So the development of high technology and high capital can provide a powerful guarantee for the development of science and technology, economy and technology of Wuhan, and it is necessary to develop.

For high technology and low capital industry, the technology content of this kind of industry is high, but the capital is relatively low, but once the pressure method is successfully put into production, it will bring high economic benefits, this kind of industry information technology and computer software industry, based on high technology, is generally high-tech research and development enterprise. But now the industry is accelerating the development of this industry is easy to become a high technology and high quality industry, it is the development of this industry, 
can greatly promote the development of service industry. For more than two kinds of high technology industry, can be called technology intensive services, but these services are still to be improved, such as information transmission, computer services and software industry, although the industry has been even more than a certain size, but there are still some problems, such as small business rules, no good market norms, the various enterprises are not good communication and cooperation, not to form mutual promotion of industrial groups.

For low tech industries, capital intensive businesses, such as wholesale and retail (Hanzheng Street) and real estate investment, capital turnover is slow. As Hanzheng Street's Wuhan commodity market, because it is a number of individual behavior, and there is no standard industry foundation, so there is no unified development model, this kind of industry if need to continue to develop, we need to innovate.

For the low tech industries, such as transportation and catering and other traditional industries, the need for a large number of human resources, but the development is not strong enough. Wuhan labor intensive services such as transportation, storage and postal industry, wholesale and retail, accommodation and catering industry, have been some development, but the overall low, backward development status, mainly because of logistics technology, information technology and other high-tech applications, small and medium enterprise financing is difficult, so the industry will encounter a lot of bottlenecks, which hinder the influx of high-tech talent, the appeal is not high, thus leading to Wuhan labor intensive service industry breakthrough platform. Although Wuhan's financial industry has recently been a steady improvement, but it has not had a far-reaching effect and influence, most state-owned large banks are not headquartered in Wuhan, fund management companies, insurance companies headquartered in Wuhan, Wuhan is not a significant shortage of foreign financial companies.

Wuhan intensive service industry is mainly in the real estate industry, water conservancy, environment and public facilities and other industries. From the real estate industry, Wuhan real estate industry is lack of funds, the market order is not standardized, which seriously affected the overall development of the real estate industry in Wuhan city. Therefore, in order to make the real estate industry in Wuhan healthy growth, not only the government guidance, market pull, but also the need for business leading behavior. Knowledge intensive service industry as a whole is like a complete ecosystem, which has a large and different level of enterprise, the enterprise and the mutual connection, mutual dependence, specialization and social cooperation, and mutual competition, survival of the fittest. Wuhan knowledge intensive service industry is still at the low level. For example, type of intermediate business financial services offered by different has amounted to more than 200 species, although the development speed is very fast, but its business scope additional value is low, only limited to agents and settlement, etc. the two traditional service aspects. Compared to some of the advantages of foreign banks in Wuhan, their advantages are more prominent, the basic occupied the high-end market in the financial services industry in Wuhan. This service industry in Wuhan should take education, information transmission and computer software service industry as the core, combined with the traditional enterprise in Wuhan, and gradually reduce the low capital low base of the industry, or to help the entire service industry cluster development.

On the whole, the service industry in Wuhan has two major characteristics, weak and weak industrial structure. But it is because of this, the service also has great development potential in Wuhan. The development of the service industry in Wuhan backward in the north of Guangzhou and other developed cities, and also behind started in Chongqing area, however, development potential is row in fourth place, Wuhan talent, technology and capital investment of service industry in the development of more favorable and future development potential is huge. Although its 
industrial structure in the whole, ranked seventh, this is because Wuhan's advantageous geographical position, is the development of transportation and other services is more perfect, but the overall service industry is still far behind in Beijing, Shanghai, Guangzhou, Shenzhen, Hangzhou, Chengdu, Chongqing, Nanjing and other cities, which is a high technology and high capital industry is still a serious shortage, so there is a lot of room for development.

\section{Development Strategy of Wuhan Service Industry}

By Gradual Development. Priority development of high technology and high capital service industry, consolidate the development of traditional service industries, and promote the development of the securities industry. Wuhan should give priority to the development of knowledge intensive services, priority for education, information transmission, computer services industry. The new growth theory thinks, twenty-first Century is "knowledge economy" era, the long-term power of economic growth is the improvement of human capital and scientific and technological innovation. The scientific and educational undertakings in Wuhan have a higher average level in the whole country, and the scientific and technological innovation ability is relatively strong, we should vigorously grasp this advantage, we need to open the private participation in science and education, organize social resources into the education industry, the introduction of competition mechanism, increase scientific research, education, and promote the improvement of the level of education. Enhance the ability of independent innovation, through the improvement of innovation. Use these innovative models to other services, such as tourism, improve the added value of tourism, give full play to the human landscape, natural landscape, ethnic customs and other resources, the development of tourism as an important industry in the development of modern service industry in Wuhan.

We should strengthen the development of traditional service industry, we should strengthen the development of traditional service industry, make full use of Wuhan unique geographical conditions, Wuhan city labor intensive service industry, mainly in transportation, wholesale and retail, Wuhan is more mature business district and Hanzheng Street wholesale and retail industry, Wuhan city government, planning commercial service facilities, to foster large-scale specialized commodity trading market, Wuhan's regional commercial center, the formation of a pleasant walk business district. At the same time, the service industry chain to the end of the industry chain to extend and penetrate, deepen the integration of emerging technologies and labor-intensive service industry, to achieve the integration of traditional services and high-tech, and gradually form a new business, such as e-commerce, online banking, etc..

For the development of the securities industry, we must continue to implement the policy of "rule of law, regulation, self-discipline, and standard", the stability of the financial insurance industry is the basis of national economic development. Regulators to improve the quality of the audit of the listing Corporation, improve the internal supervision system of securities companies, learning from foreign advanced management experience, training and introduction of high-quality professional management personnel, improve the level of information, and continuously improve the use of insurance funds management level.

Establish a Government Guidance, Market Driven, Driven by Business Model. The development of modern service industry must be based on the development of the market economy, the government should improve the industrial policy as soon as possible to guide the modern service industry to form a reasonable industrial gathering area, to achieve the scientific layout of the target. Market is the most effective driving that mode, so when the government should pay attention to the guidance of the market to set a scientific and reasonable economic growth target, because the service industry accounted for GDP, investment and economic growth fell inevitable, such as 
Beijing, Shanghai and other places due to the service industry accounted for a substantial increase in economic growth fell to a lower level, but it is because of the effective solution to the employment problem, although economic growth rate has declined, but the overall view will not cause a huge impact on the economy. Government can guide enterprises to use e-commerce, logistics, financial innovation and development in the field, in order to reduce the operating costs of enterprises, so as to promote enterprise restructuring and upgrading, can improve the livelihood of the people, while reducing the price of service industry.

In order to ensure the steady development of agriculture and industry, the service industry and other industries are coordinated and balanced development. In the future, we must have the advantages of developing human capital. In the premise of maintaining the stability of the final consumer service industry, we can accelerate the development of intermediate service industry, not only can effectively promote the overall development of the service industry, but also conducive to the coordination of the structure of the three industries.

Actively Play a Regional and Inter Industry Interaction. Wuhan's service industry development not only affects the development of service industry in other eight cities, but also the impact of these eight cities, of course, Wuhan city as the backbone of the rise of central China, but also to keep the service industry in neighboring provinces, in the case of no account of the development of urban services, Wuhan City, the radiation range of services by 7 cities. Wuhan in Guangzhou and Chongqing, Xiangtan, Loudi and Zhangjiajie, Jiangxi and Ji'an, Hunan, Ji'nan and Xi'an, but the radiation range expanded to Pingdingshan and Henan in Zhoukou province.

Wuhan is as the capital of Hubei Province, the only sub provincial cities in the central and lower reaches of the Yangtze River in the large cities, and vigorously develop the service industry, improve the service industry, comprehensive radiation, Wuhan service industry is limited, but the radiation area is vast. Wuhan should rely on the huge potential of talents, investment funds and technology brought strong, strengthen planning guidance, the formation of industrial agglomeration layer distribution structure, relying on professional park project investment, efforts to enhance the professional financial services, logistics, information, such as the level of development of producer services, with the application of modern information technology to strengthen the business, real real estate, tourism and other life service industry environment supporting role, through the implementation of the strategy of going out and bringing in, rely on the joint development of international and domestic, foreign and local enterprises, to enhance the Wuhan services comprehensive radiation and overall economic development level as the goal, to promote the regional center of the city of Wuhan radiation leading role, and then realize the Wuhan renaissance.

Wuhan city services range but size is generally lower, industry whole competition fierce and most of the knowledge service industry in unsupervised, no coordination, exacerbated by the industry of the scattered degree. Wuhan's service industry is mainly based on the knowledge intensive industry, while the low cost, high profit attract many speculators, such as many fund companies. Through the reasonable arrangement of the organization, to maximize the promotion of knowledge transfer, and shorten the space between the two sides of the industry and knowledge gap. In order to promote the integration of the industry, the development of the service industry is not balanced, the government should have a selective support for some new knowledge intensive services, such as the legal profession, the use of talents to enrich their own advantages, strengthen the construction of infrastructure, innovation and some high end financial services products, and make full use of technology and industry integration to promote the development of high-end services, spawned a number of high technology intensive service industry. 
Actively Promote Urbanization and Promote Urbanization and Service Industry Interaction. Wuhan city resident population urbanization is rate of $67.6 \%$, the household population urbanization rate of $79.3 \%$, the requirements of building a moderately prosperous society, there is still a lot of space. The law of the development of international urbanization, the urbanization rate of $30 \%$ to $70 \%$ is the rapid development of urbanization, the urbanization of our country is at this stage, the rapid development of urbanization is entirely possible. Throughout the history of urbanization, it is a kind of industrial structure and the transformation of its spatial distribution, it is the traditional mode of production, life style and behavior way to modern production mode, life style and behavior way. Service consumption comes from a variety of transactions, the people of the past, the kind of life in the past, the way of life will be changed, so as to release the service consumption and service supply, service market demand can be expanded exponentially. In order to provide an ideal space for the service industry, the city has a large effect on both the population and various factors, and the huge service demand and the scale effect. Therefore, it is very important to promote the urbanization process in order to create a good space form and carrier for the development of service industry.

Deepen the Division of Labor and Cooperation, and Promote the Integration of the Service Industry and Manufacturing, and focus on the Development of Producer Services. In the course of industrialization in developed countries, producer service industry has shown strong core competitiveness and innovation activity in the modern economy, and played a role in the service industry and manufacturing industry, which plays a role in the development of the national economy. Service industry in the GDP accounted for more than a sustained growth in the manufacturing sector is likely to become the norm, but China is still in the accelerated development of industrialization and transformation stage, industrialization road is still long. From the experience of developed countries, this stage can take the manufacturing industry and the production service industry "two wheel drive" and integration of the development of the road. This requires that the high-end service elements are firmly embedded in the manufacturing industry, through the production of services to promote the transformation and upgrading of manufacturing industry. In the modern industrial system, material production needs to be related to the production of service industry, its development and growth will also produce the service industry, especially financial capital and human capital as the guide, through the use of and research and development, logistics, marketing and other aspects of coordination and interaction, to turn into material wealth. Similarly, the realization of the service mode, service behavior of the completion of the manufacturing industry can not be separated from the material carrier. Services and products are mutually dependent, to meet the needs of the market.

Comprehensively Deepen the Reform of the Service Sector, the Release of Service Industry Productivity. At present, the intangible service products or technology, knowledge and labor service trade in Wuhan City, supply and demand sides information asymmetry is more common, therefore, it is more dependent on good institutional environment and market order. The system construction and innovation of service industry in our country is lagging behind, the concrete performance is generally rigid, the market is not high, the degree of social division of labor is lower. To promote the service industry system and mechanism innovation, deepen the reform of the service industry, it is necessary to actively open up the market, to break the monopoly of the industry, to encourage the elements of competition, strengthen market supervision, improve the government regulation, through the reform of the service sector continued to grow in space and potential.

Reform and Innovation of Vocational Education System, to Provide Qualified Personnel for the Rapid Development of the Service Industry. The development of modern service industry requires a lot of talented people who are able to understand technology, management, and good 
operation, which can not meet the existing school running mode. Therefore, we must change the practice of the neglect of vocational education, establish vocational education must be market-oriented philosophy, adhere to the employment oriented, establish a new mechanism and teaching mode. For example, the establishment of colleges and enterprises cooperation in personnel training, implement the system according to the enterprise with "orders" new model of education and training, rather than simply by the school "behind closed doors". From the awareness of the strengthening of service industry personnel training in an important position, and strive to innovate the service industry personnel training mechanism, and strive to create a number of high-level, high skills, familiar with modern business philosophy of service industry professionals.

\section{Conclusion}

To draw a conclusion, the service industry of Wuhan city have a bit backward comparing with other developed cities within China, such as Beijing, Shanghai and Shenzhen. The main service industries in Wuhan are the educational industry, computer service and software, and other scientific research services, wholesale and retail, traditional services. To solve the problems of service industry in Wuhan, we must consider from two aspects: technology and capital.

\section{Reference}

[1] Colin Clark. The Conditions of Economic Progress. London: Macmillan\&Co. Ltd. 1951.

[2]Scott, A. J. Flexible Production Systems and Reffional Development: the Rise of New Industrial Spaces in North American And Western Europe. International Journal of Urban and Regional Researchl2: (1988), 171-186.

[3]I. Miles, N, Kastrinos, R. Bilderbeek, P. denHertog, K. Flanagan and W. Huntink. Knowledge Intensive business services: neir roleUSel'8, carriers and SOUI'CIof innovafion. Report to the EC DG XlllLuxembourg: Sprint EIMS. Programme, 1995.

[4] Wood, P.A. Flexible Accumulation and the Rise of Business Services. Transactions of the Institute of British Geographers.1992, 16: 160-173. 